\title{
Immigrant Newborn and Physiological Jaundice
}

\section{Antonio A Zuppa, Maria Cavani, Riccardo Riccardi, Piero Catenazzi, Alma lafisco and Giovanni Vento}

Department of Pediatrics, Division of Neonatology, Catholic University of the Sacred Heart, Rome, Italy

\section{Abstract}

Objective: In Italy there are a growing number of infants born to non-Italian mothers. The aim of this study is to analyze the physiological trend of bilirubin in newborns from South-east Asia and South America, compared to Italian newborns.

Method: 60 newborns were enrolled: 20 Italian newborns, 20 South American newborns, 20 Southeast Asian newborns. All babies were born from normal pregnancies, delivered vaginally. There was no $A B 0$ and Rh incompatibility. Daily total serum bilirubin (TSB) levels were the main outcome.

Results: The bilirubin reached the peak on the third day of life in the Italian group $(9.5 \pm 2.7 \mathrm{mg} / \mathrm{dL})$; on the fourth day of life in the Southeastern Asian group $(9.9 \pm 3.0 \mathrm{mg} / \mathrm{dL})$ and on the fifth day of life in the South American group $(10.9 \pm 2.4 \mathrm{mg} / \mathrm{dL})$.

On the fifth, sixth and seventh day of life South American newborns had significantly higher TSB levels compared to the Italian group and to the Southeastern Asian group.

Conclusion: The higher and delayed peak of bilirubin level in infants from Southeastern Asia and South America has epidemiological and health-care consequences. Dedicated nomograms should be processed to avoid the overtreatment and the discharge of newborns with a higher and later peak of bilirubin.

Keywords: Newborn; Physiological jaundice; Immigrant mother; Bilirubin

\section{Introduction}

Nowadays in Italy, there are a growing number of infants born to non-Italian mothers, reflecting the increase of foreign residents in our country [1]. This trend is confirmed by the "A. Gemelli" hospital in Rome, where this study was conducted: infants born to foreign parents in the last five-years were between 20 and $25 \%$ of the total [2].

This trend has a significant role in clinical care, both for the mother and the newborn. Neonatal jaundice seems particularly relevant in some ethnic groups, such as Southeast Asian people and Latin American ones and less in others, such as in Africans [3-6].

The aim of this study was to analyze the physiological trend of bilirubin in the first seven days of life in newborns from Southeast Asia and in newborns from South America, in relation to the Italian population, to evaluate the differences between the populations concerned, and to minimize the overtreatment and the medicalization of normal newborns.

\section{Method}

We studied 60 newborns: 20 Italian, 20 of Southeast Asian ethnicity, 20 from South America. These infants, delivered in Gemelli Hospital between October 2010 and August 2011, had the following characteristics: they were born from normal pregnancy, delivered vaginally, Birth weight $>2,500 \mathrm{~g}$ and appropriate for gestational age, Absence of $\mathrm{AB} 0$ and $\mathrm{Rh}$ incompatibility, Direct Coombs test negative, Apgar score $\geq 6$ at $1 \mathrm{~min}$ and at $5 \mathrm{~min}$ after birth, direct bilirubin (measured on the third day of life) $<1 \mathrm{mg} / \mathrm{dL}$.

All patients included had both parents belonging to the same ethnic group. The countries of origin in groups of children of immigrant mother were respectively: Southeast Asia (Bangladesh, China, Philippines, India, Sri Lanka, Pakistan) and South America (Bolivia, Ecuador, Peru, Venezuela, Paraguay).

All infants were predominantly or exclusively breastfed. Newborns with a weight loss of $>8 \%$ were excluded from the study.
There were no statistically significant differences between the three groups studied with respect to gender, gestational age and birth weight.

Total serum bilirubin was measured every day for the first seven days of life, even after discharge, using a direct spectrophotometric method (Twin Beam Plus-Ginevri) and heparinized capillaries.

On the third day of life direct bilirubin was measured in all newborns, using the colorimetric method.

We considered the average of the maximum value of bilirubin reached by infants in the Italian population and in the immigrant groups, and the average hours of life when the maximum peak of bilirubin was reached.

All data were prospectively collected and stored on a database. Continuous variables were presented as mean \pm standard deviation (SD) and categorical variables as percentage. Comparisons with the variables were performed using Student's T-test in case of normal distribution. Significance was accepted at $\mathrm{p}<0.05$. Statistical analyzes were performed using the software Graph Pad 4.

Study protocol was approved by the Ethics Committee of the Gemelli Hospital.

Informed consent was obtained from all parents of infants enrolled in the study.

*Corresponding author: Riccardo Riccardi, Department of Pediatrics, Division of Neonatology, Catholic University of the Sacred Heart, Rome, Italy, Tel: +390630154357 Fax: +39063383211; E-mail: riccardo.riccardi@live.it

Received June 13, 2017; Accepted July 01, 2017; Published July 10, 2017

Citation: Zuppa AA, Cavani M, Riccardi R, Alma PC, Vento IG (2017) Immigrant Newborn and Physiological Jaundice. J Neonatal Biol 6: 258. doi:10.4172/21670897.1000258

Copyright: @ 2017 Zuppa AA, et al. This is an open-access article distributed under the terms of the Creative Commons Attribution License, which permits unrestricted use, distribution, and reproduction in any medium, provided the original author and source are credited. 


\section{Results}

The trend of serum bilirubin in the first seven days of life in the entire population studied was similar to what has already been described in other medical reports: it highlights the classic biphasic trend of the levels of bilirubin. The mean maximum peak of bilirubin was $9.9 \mathrm{mg} / \mathrm{dL}$ and it was reached on the fourth day of life.

In the first phase, the rapid increase of the bilirubin is due to a higher rate of bilirubin production than adults, associated with a limited ability to conjugate bilirubin, which is the limiting step in this phase. During the slow decrease of serum bilirubin, the mechanisms of excretion is probably represented by a speed-limiting step, and it needs to be activated with an induction mechanism, as well as the conjugation $[7,8]$.

Considering separately the three subpopulations, in the Italian group this trend was even more evident: the bilirubin increased rapidly to reach the peak on the third day of life, with mean values of $9.5 \pm 2.7$ $\mathrm{mg} / \mathrm{dL}$ (Figure 1).

In the South-East Asian ethnic group, the peak of serum bilirubin occurred on the fourth day of life, with a mean of $9.9 \pm 3.0 \mathrm{mg} / \mathrm{dl}$, respecting the characteristic biphasic trend (Figure 1).

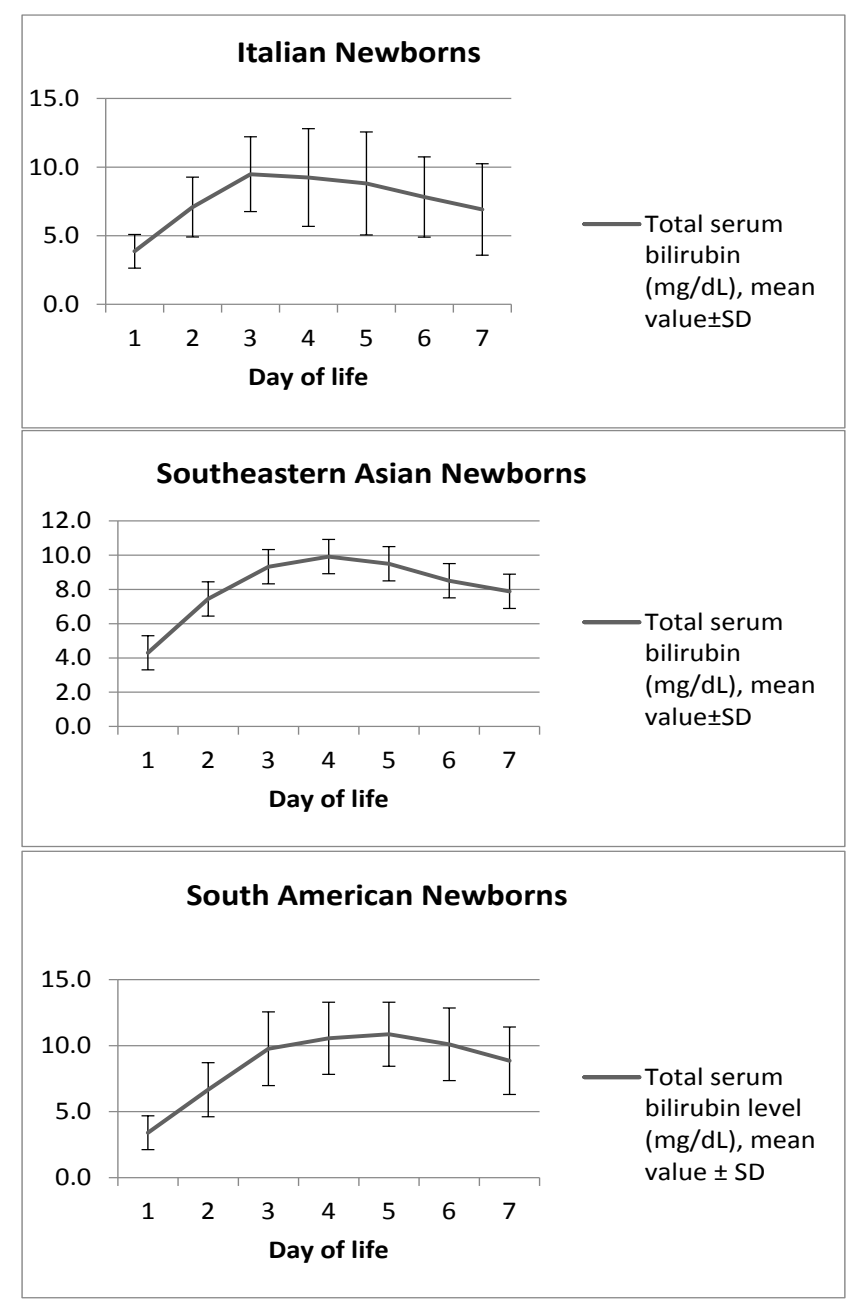

Figure 1: Trend of serum bilirubin in the first seven days of life in the 3 populations.
In the newborns of South American ethnicity, the maximum value of serum bilirubin was recorded on the fifth day, and the mean value was $10.9 \pm 2.4 \mathrm{mg} / \mathrm{dL}$ (Figure 1). The peak of bilirubin was earlier and less pronounced in Italian infants, especially compared with infants from South America, who had a higher and later peak. Infants from South-East Asia are placed in an intermediate position compared to the other two groups.

Five Italian newborns (25\%), six infants $(30 \%)$ in the Southeast Asian group and six infants (30\%) in the South American group had hyperbilirubinemia, defined as a level of total bilirubin $\geq 12 \mathrm{mg} / \mathrm{dL}$ [8]

The mean maximum value in infants who had a TSB level of $>12$ $\mathrm{mg} / \mathrm{dL}$ was almost the same in the three ethnic groups $(14.7 \pm 1.0 \mathrm{mg} /$ $\mathrm{dL}$ in Italian newborns, $14.1 \pm 1.3 \mathrm{mg} / \mathrm{dL}$ in infants from Southeastern Asia, $14.7 \pm 1.5 \mathrm{mg} / \mathrm{dL}$ in South American infants).

Two Italian newborns (10\%), three newborns in the South American group (15\%), two newborns in Southeast Asian group (10\%) reached a bilirubin level of $\geq 15 \mathrm{mg} / \mathrm{dL}$.

For none of the infants examined treatment with phototherapy and/or exchange transfusion was necessary.

Considering the daily values of bilirubin, on the fifth, sixth and seventh day of life in South American group had significantly higher TSB levels compared to the Italian group and to the Southeast Asian group. There were differences between the Italian group and the Southeastern Asian group, but they were not statistically significant (Table 1 and Figure 2).

Focusing on the number of hours when the peak of bilirubin was reached in the three groups, we observed that it occurred later in newborns from South America compared with Italian and Southeastern Asian populations (respectively $105 \pm 19 \mathrm{~h} v s .72 \pm 20 \mathrm{~h}, \mathrm{p}<0,0001$ and $105 \pm 19$ h vs. $82 \pm 20 \mathrm{~h}, \mathrm{p}=0,0012$ ).

We performed multivariate regression analysis for confounding factors such as birth weight, gender, gestational age and type of lactation and we didn't find interference with the final results.

The trend of physiological weight loss was almost the same in the three groups, suggesting the absence of influence on physiologic neonatal jaundice: on the second day of life the mean weight loss was $3.5 \%$ in the Italian group, 3.4\% in the Southeast Asian group and 3.7\% in the South American group; on the third day after birth it was 5.9\% in the Italian group, $5.4 \%$ in the Southeast Asian group and $6.1 \%$ in the South American group.

\begin{tabular}{|c|c|c|c|c|c|c|}
\hline \multirow{3}{*}{$\begin{array}{l}\text { Total serum } \\
\text { bilirubin } \\
\text { (mg/dl) } \\
\text { Mean value } \\
\pm \text { SD }\end{array}$} & & & & \multicolumn{3}{|c|}{$\mathbf{p}$} \\
\hline & A & B & C & A vs. B & B vs. C & A vs. C \\
\hline & $\begin{array}{l}\text { Italian } \\
(n=20)\end{array}$ & $\begin{array}{c}\text { South } \\
\text { American } \\
(n=20)\end{array}$ & $\begin{array}{l}\text { Southeastern } \\
\text { Asian }(n=20)\end{array}$ & & & \\
\hline $1^{\circ}$ day & $3.9 \pm 1.2$ & $3.4 \pm 1.2$ & $4.3 \pm 2.2$ & ns & ns & ns \\
\hline $2^{\circ}$ day & $7.1 \pm 2.1$ & $6.7 \pm 2.0$ & $7.4 \pm 2.8$ & ns & ns & ns \\
\hline $3^{\circ}$ day & $9.5 \pm 2.7$ & $9.8 \pm 2.7$ & $9.3 \pm 2.4$ & ns & ns & $\mathrm{ns}$ \\
\hline $4^{\circ}$ day & $9.2 \pm 3.5$ & $10.6 \pm 2.7$ & $9.9 \pm 3.0$ & ns & ns & ns \\
\hline $5^{\circ}$ day & $8.8 \pm 3.7$ & $10.9 \pm 2.4$ & $9.5 \pm 2.9$ & 0.04 & 0.04 & ns \\
\hline $6^{\circ}$ day & $7.8 \pm 2.9$ & $10.1 \pm 2.7$ & $8.5 \pm 2.9$ & 0.01 & 0.01 & ns \\
\hline $7^{\circ}$ day & $6.9 \pm 3.3$ & $8.9 \pm 2.5$ & $7.9 \pm 3.1$ & 0.03 & 0.03 & ns \\
\hline
\end{tabular}

Table 1: Daily bilirubin values in the three ethnic groups. 


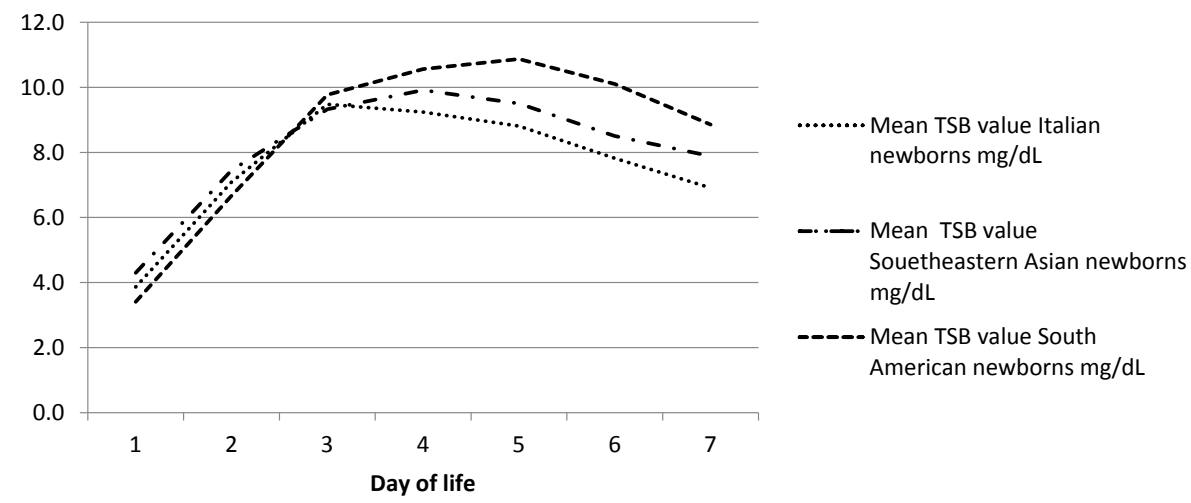

Figure 2: Comparison between the three ethnic groups.

The mean maximum body weight loss in the entire population was $5.8 \%$, and it was reached on the 3 rd day of life.

\section{Discussion}

Our data show that the trend of physiological jaundice in newborns from Southeast Asia and South America is different from Italian infants. In newborns born to immigrant mothers, there was a higher and more delayed peak of bilirubin than in Italian infants. This is even more evident examining data of the South America newborns, which had the maximum value of bilirubin higher (although not statistically significant) and later than Italian newborns and Southeast Asian infants (respectively $105 \mathrm{~h} v s .72 \mathrm{~h}, \mathrm{p}<0.0001$ and $105 \mathrm{~h} v s .82 \mathrm{~h}, \mathrm{p}=0.0012$ ).

There are many studies showing a higher incidence, extent and duration of neonatal jaundice in newborns of Asian ethnicity, while newborns from South America have not yet been studied.

In 1965, Brown and Wong in a study conducted on a population of four different ethnic origins (British, Chinese, Malay, Indian) reported a higher level of bilirubin, longer duration of hyperbilirubinemia and a later peak of TSB in the Asian population, suggesting that the reason could be the immaturity or the inhibition of the enzymatic system for the conjugation of bilirubin. The neonatal jaundice in Asian infants very often exceeds the limits of physiological jaundice in Caucasian infants, both in intensity and in duration; this phenomenon, however, cannot correlate to pathological conditions. Although the peak of bilirubin is higher and longer, TSB descends spontaneously, without the risk of neurological sequelae and without need for treatment [3].

In 1985 Linn, in a study of Caucasian, Black and Asian newborns showed that the Asian infants have a higher risk of hyperbilirubinemia and TSB level $>15 \mathrm{mg} / \mathrm{dL}$ compared to Caucasians [9].

In 2002 Setia et al. showed that Asian infants are $37 \%$ more likely to develop jaundice than Caucasians [10].

In recent years there was a lot of interest to research the specific causes of neonatal jaundice in the population of Asian ethnicity, but much less for infants from South America.

Akaba et al. in 1999 showed that the mutation Gly71Arg in the UGT (UDP glucuronosyl transferase) is prevalent in Japanese, Korean and Chinese populations. It is seen more frequently in patients with neonatal hyperbilirubinemia than in the control group [11].

Huang et al. in 2002 in a cohort study showed the impact of the presence of both the G6PD (Glucose-6-phosphate dehydrogenase) enzyme deficiency and the A (TA) 7TAA variant of the promoter region of the gene of the enzyme UDP-glucuronosyl in the Taiwanese population, suggesting an additive role of the two genetic defects in hyperbilirubinemia [12].

In 2003, Weng et al. in a cohort study demonstrated that healthy infants at term born in Taiwan with G6PD deficiency have a higher incidence of hyperbilirubinemia (defined as TSB $>15 \mathrm{mg} / \mathrm{dL}$ ) [13].

In 2004 Huang et al. showed that newborns with the 211 mutation of UGT1A1 and 388 of OATP2 (Organic anion transporting polypeptide 2) have a high risk of developing severe hyperbilirubinemia in the Taiwan population [14]. The G6PD deficiency may also explain the higher incidence of neonatal jaundice in South America populations. In 2006 Castro, Weber et al., in a study of 2799 infants, reported a total deficit of enzyme activity in $1.4 \%$ of patients, an intermediate form in $6.4 \%$, while the remaining $92.2 \%$ had a normal G6PD [15]. The awareness that $7.9 \%$ of infants in southern Brazil have a deficit, absolute or partial, of the activity of G6PD is important to organize screening programs and a correct management of jaundice in the early days of life.

In the population we studied, the three groups of infants did not differ in the two most important risk factors for an accentuation of neonatal jaundice: all infants were breastfed, exclusively or predominantly, and weight loss in the three populations was similar [16-18].

The higher and delayed peak of bilirubin levels in infants from South-East Asia and South America has epidemiological and health care consequences: this can lead to later dismissal from hospital, especially in infants of ethnic South American compared with Italian infants.

Jaundice is the more frequent clinical event in the neonatal period: in a healthy infant the rate of hyperbilirubinemia is about $15-20 \%$ [19]. In most cases jaundice does not cause problems for a child's health. It requires monitoring, because it can cause serious neurological damage, or it can be the sign of a significant organic pathology [20].

In a recent study about the hyperbilirubinemia in newborns of immigrant mothers, Zuppa et al. showed that the hospitalization was significantly longer by approximately one day in infants from SouthEast Asia and South America than in Italian infants (4.5 days vs. 3.6 days, $\mathrm{p}<0.0001$ and 4,2 days $v s$. 3.6 days $\mathrm{p}=0.0004$ ) [21].

There are nomograms for the bilirubin levels in the Italian population which are taken into consideration for a protected discharge and to determine the timing of the follow-up. Medical journals do not 
Citation: Zuppa AA, Cavani M, Riccardi R, Alma PC, Vento IG (2017) Immigrant Newborn and Physiological Jaundice. J Neonatal Biol 6: 258. doi:10.4172/2167-0897.1000258

show specific nomograms regarding other ethnic groups: it would be useful to adjust the curves of Italian newborns to infants of other ethnicity.

The other result of this study is related to the levels of bilirubin for which a treatment with phototherapy and/or exchange transfusion must start: since the newborns born to immigrant mothers seem to have a higher and later peak of bilirubin, it could be useful in clinical practice to start treatment at a greater number of hours after birth and for higher values of bilirubin, with the objective to avoid the overtreatment of normal newborns and the discharge of infants who may have a later peak.

\section{Conclusion}

Therefore, physicians should be adequately informed and prepared to apply any new care protocols specific to immigrant ethnic groups. The results obtained with this study should be confirmed on broader and more homogeneous populations in order to process dedicated nomograms.

\section{References}

1. ISTAT - Istituto nazionale di statistica (2011) La popolazione straniera residente in Italia al $1^{\circ}$ gennaio

2. Zuppa AA, Orchi C, Calabrese V, Verrillo G, Perrone S, et al. (2010) Maternal and neonatal characteristics of an immigrant population in an italian hospital. $J$ Matern Fetal Neonatal Med 23: 627-632.

3. Brown WR, Boon WH (1965) Ethnic group differences in plasma bilirubin levels of full-term, healthy Singapore new-borns. Pediatrics 36: 745-751.

4. Osborn LM, Reiff MI, Bolus R (1984) Jaundice in the full-term neonate. Pediatrics 73: 520-525.

5. Hodgman JE, Edwards N (1992) Racial differences in neonatal jaundice. Hyperbilirubinemia in Hispanic Infants - A survey. Clin Pediatr 31: 719-722.

6. Brown AK (1992) Hyperbilirubinemia in black infants - Role of glucose-6phosphate dehydrogenase deficiency. Clin Pediatr (Phila) 31: 712-715.

7. Gartner LM, Lee KS, Vaisman S, Lane D, Zarafu I (1977) Development of bilirubin transport and metabolism in the new-born rhesus monkey. J Pediatr 90: 513-531.
8. MacDonald MG, Seshiua MK, Mullet MD (2006) Avery's neonatology Pathophysyology and management of the new-born. Lippincott William and Wilkins.

9. Linn S, Schoenbaum SC, Monson RR, Rosner B, Stubblefield PG, et al. (1985) Epidemiology of neonatal hyperbilirubinemia. Pediatrics 75: 770-774.

10. Setia S, Villaveces A, Dhillon P, Mueller BA (2002) Neonatal jaundice in Asian, white and mixed-race infants. Arch Pediatr Adolesc Med 156: 276-279.

11. Akaba K, Kimura T, Sasaki A, Tanabe S, Wakabayashi T, et al. (1999) Neonata hyperbilirubinemia and a common mutation of the bilirubin uridine diphosphateglcorunosyl transferase gene in Japanese. J Hum Genet 44: 22-25.

12. Huang CS, Chang PF, Huang MJ, Chen ES, Chen WC (2002) Glucose-6phosphate dehydrogenase deficiency, the UDP-glucoronosyl transferase $1 \mathrm{~A} 1$ gene, and neonatal hyperbilirubinemia. Gastroenterology 123: 127-133.

13. Weng YH, Chou YH, Lien RI (2003) Hyperbilirubinemia in healthy neonates with glucose-6-phosphate dehydrogenase deficiency. Early Hum Dev 71: 129136 .

14. Huang MJ, Kua KE, Teng HC, Tang KS, Weng HW, Huang CS (2004) Risk factors for severe hyperbilirubinemia in neonates. Pediatr Res 56: 682-689.

15. Castro S, Weber R, Dadalt V, Tavares V, Giugliani R (2006) Prevalence of G6PD deficiency in new-borns in the south of Brazil. J Med Screen 13: 85-86.

16. Gourley GR (2002) Breast-feeding, neonatal jaundice and kernicterus. Semin Neonatol 7: 135-141.

17. Zuppa AA, Fracchiolla A, D'Andrea V Sindico P, Cota F, et al. (2007) Allattamento e ittero: Stato dell'arte. Acta Neonatologica and Pediatrica 1: 3337.

18. Maisels MJ, Gifford K (1986) Normal serum bilirubin levels in the new-born and the effect of breast-feeding. Pediatrics 78: 837-843.

19. Sciuto M, Bertino G, Zocco M, Vecchio I, Raffaele R, et al. (2009) Incidence and causes of neonatal hyperbilirubinemia in a center of Catania. Ther Clin Risk Manag 5: 247-250.

20. AAP Subcommittee on Neonatal Hyperbilirubinemia (2001) Neonatal jaundice and kernicterus. Pediatrics 108: 763-765.

21. Zuppa AA, Catenazzi P, Orchi C, Cota F, Calabrese V (2013) Hyperbilirubinemia in healthy new-borns born to immigrant mothers from south-eastern Asia compared to Italian ones. Indian J Pediatr 80: 455-459. 